\section{Hiperpublicidade nas Redes sociais com o Covid-19: baixa de credibilidade da Rede Globo}

\author{
Hyper-consumption on social networks with Covid- \\ 19: low credibility of Rede Globo
}

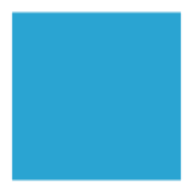

Revista

Extensão em Foco
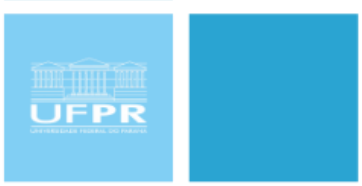

ISSN $2358-7180$

Eliane Meire Soares Raslan ${ }^{1}$, Milena Mariana de Oliveira ${ }^{2}$

\begin{abstract}
RESUMO
Este estudo trata da repercussão nas redes sociais televisivas, no período de Isolamento Social no ano de 2020. Momento de alta repercussão política, e que no Brasil tem sido associado ao atual governo Bolsonaro, gerando muitas divergências e intrigas opinativas entre as mídias sociais, desde o início da última eleição presidencial. Verificamos que as notícias apresentadas pela Rede Globo vêm sofrendo uma série de questionamentos quanto a sua veracidade, por parte de alguns grupos de telespectadores. Dessa forma, torna-se evidente que as falas políticas interferem na credibilidade comunicacional das emissoras e como estas informam sobre o Covid-19. O objetivo é entender as associações que estes indivíduos fazem ao atacar a emissora. Verificamos que Rede Globo tem sido afetada diretamente nas redes sociais, especialmente por sites que utilizam como base de dados, fontes que não são consideradas seguras, mesmo assim, devemos considerar que estes vão interferir nas opiniões, e entendemos como uma tendência ao HiperConsumo da sociedade contemporânea, porém não realizada por profissionais de publicidade.
\end{abstract}

Palavras-chave: Fake News. Hiperconsumo. Redes Sociais. Credibilidade Comunicacional.

\title{
ABSTRACT
}

This study deals with the repercussion in the social television networks, in the period of Social Isolation in the year of 2020. Moment of high political repercussion, and that in Brazil has been associated to the current Bolsonaro government, generating many divergences and opinion intrigues between social media, since the beginning of the last presidential election. We found that the news presented by Rede Globo has been suffering a series of questions regarding its veracity, by some groups of viewers. Thus, it becomes evident that the political statements interfere with the communicational credibility of the broadcasters and how they report on Covid-19. The goal is to understand the associations that these individuals make when attacking the broadcaster. We found that Rede Globo has been directly affected on social networks, especially by sites that use databases as sources, which are not considered safe, even so, we must consider that these will interfere in opinions, and we understand it as a tendency to Hiper-sonsumption in contemporary society, but not carried out by advertising professionals.

Keywords: Fake News. Hyper-consumption. Social Networks. Communicational Credibility.

\footnotetext{
${ }^{1}$ Doutora em Comunicação Social. Profa. e Pesquisadora. Universidade do Estado de Minas Gerais UEMG. Divinópolis, Minas Gerais, Brasil. Coordenadora do Centro CEPCCOM e líder do Grupo PROLIM - Imagens Midiáticas. Editora da Revista FANDOM. Link: <https://cepccomuemg.wixsite.com/cepccom/grupos-depesquisa> Acesso em: 10 agosto 2020. E-mail: eliane.raslan@uemg.br. Lattes: http://lattes.cnpq.br/3081335079399561 Orcid: https://orcid.org/0000-0002-2274-2836

${ }^{2}$ Curso em Comunicação Social - Publicidade e Propaganda. Universidade do Estado de Minas Gerais. Divinópolis, Minas Gerais, Brasil. E-mail: milenamarianaoliver@gmail.com. E-mail: autor2@email.com. Orcid: https://orcid.org/0000-0001-7317-6793
} 


\section{INTRODUÇÃO E MÉTODO}

Este estudo faz parte das pesquisas realizadas pelo grupo de estudo PROLIM - Imagens Midiáticas (CEPCCOM, 2019), cadastrado pelo CNPq, que buscou informações sobre as repercussões televisivas neste momento de isolamento social, a partir do Projeto de Extensão ${ }^{3}$, vinculado a Universidade UEMG, Unidade Divinópolis/MG. O projeto busca registrar situações a partir da fotografia, sendo a comunicação abordada na propaganda e/ou no jornalismo, logo, este primeiro resultado serve como base para um futuro planejamento na prática fotográfica do jornalismo, inicialmente buscamos entender parte da comunicação jornalística neste período de pandemia, divulgando resultados de pesquisa quanto as repercussões em torno emissora televisiva Rede Globo, quanto as repercussões políticas e comunicacionais. Se antes as pessoas estavam acostumadas a alimentar a internet com posts sobre o dia a dia e a acreditar - embora existam desde os primórdios da comunicação de massa, alguns questionamentos sobre a confiabilidade destes veículos comunicativos - em se não todas, em pelo menos a grande maioria, das informações que absorviam navegando on-line ou através de programas televisionados, em 2020 tais questionamentos começaram a se acentuar de forma mais visível, o que trouxe grandes mudanças para os processos comunicativos e para a vida da população. Conforme site da ANAHP (2020), a Associação Nacional de Hospitais Privados, no dia 01 de dezembro de 2020, a cidade de Wuhan, na China, confirmou o primeiro caso do novo Coronavírus, também conhecido como covid-19, mesmo assim, ainda carece de maiores estudos para confirmar se o vírus iniciou realmente na China, podendo existir outras hipóteses, como ser levado de outro país por turistas, ou mesmo, por translado na área comercial. A partir desse dia, muita coisa começou a mudar, uma doença totalmente desconhecida e silenciosa estava se espalhando rapidamente. Segundo a linha do tempo publicada pelo site Sanar Med (2020), em apenas três meses todos os continentes - com exceção da Antártida - já haviam sido contaminados, e o mundo já somava mais de 190 mil doentes com sintomas da covid-19. Outrossim, os impactos da nova pandemia começaram a ser sentidos no Brasil somente a partir do dia 26 de fevereiro do ano de 2020, quando o primeiro caso da doença foi confirmado no país, no estado de São Paulo. Ainda segundo a linha do tempo, no dia 11 de março o Ministério da Saúde (2020) regulamentou os critérios de isolamento social e quarentena, que deveriam ser adotados pelas autoridades sanitárias do país e consequentemente,

\footnotetext{
${ }^{3}$ Projeto de Extensão, titulado: "Fotografia publicitária e jornalística como objeto de extensão: creche e lar do idoso, um olhar com identidade, representação e produção de sentido". Aprovado pelo Edital 01/2019 e 01/2020 PAEX/UEMG. Iniciou em março de 2019.
} 
a partir da data em que as regulamentações do Ministério da Saúde, feitas pelo então ministro Luiz Henrique Mandetta, foram publicadas no DOU, Diário Oficial da União, o dia a dia dos brasileiros começou a mudar severamente.

Sendo assim, seguindo as recomendações do Ministério da Saúde (2020), as pessoas mudaram completamente suas rotinas, uma parte da população passou a trabalhar em casa no modelo Home Office, elas deixaram de frequentar e/ou diminuíram a constante de frequência a bares, restaurantes, academias, praças públicas e outros serviços considerados não essenciais - estes proibidos a abertura posteriormente, para evitar a propagação da doença. Nesse sentido, os acessos as redes sociais têm aumentado, isto se deve ao fato de que em 2020 os ideais de rotina e controle foram alterados. Levantamos reflexões pertinentes sobre a forma como a comunicação está ocorrendo nas redes sociais, será que as emissoras de comunicação estão preocupadas com o estado emocional do indivíduo neste momento ou somente denunciar é o mais importante? Destaque para assuntos associados a felicidade poderiam diminuir os ataques nas redes? Será que nos indivíduos comuns, estamos valorizando as pessoas e os momentos certos? Será que estávamos nos expondo mais do que o necessário nas redes sociais? E principalmente, será que devemos acreditar em tudo o que vemos nas mídias? A comunicação falsa neste momento de pandemia mundial, é muito grave, já que uma enorme parcela da sociedade está em isolamento social, deixando de relacionar diretamente e alterando seus modos de comunicação.

O simples fato do comunicar da população nas redes torna-se um ato, pode gerar uma ocorrência e suscitar circunstâncias, mas acima de tudo, destacamos o respeito quanto ao uso das fontes verídicas. Nossa abordagem dos fake news não tem partido político, não há intenção de questionar a direita ou esquerda, por exemplo, mas sim, o quanto membros de partidos e o próprio cidadão (eleitor), devem refletir da importância da comunicação com ética e veracidade nas redes, sobretudo como uma consequência da HiperConsumo e/ou da HiperPublicidade, já que quando feita de maneira tendenciosa acaba por beneficiar determinadas pessoas ou ideologias, como também, utilizada algumas vezes como ferramenta de controle e manipulação das informações destinadas a massa populacional, estes termos podem se tornar uma arma de controle midiático, a partir de discursos mal intencionados e muitas vezes não verídicos, apoiados pelas grandes redes de comunicação e que podem trazer serias consequências para a sociedade. Diante do uso dos termos HiperPublicidade e HiperConsumo, vão perceber no final deste estudo, que são termos como o mesmo sentido, o primeiro, parte da promoção para o 
consumo e o segundo do consumo pela promoção, mesmo com direcionamentos distintos, as considerações se esbaram. HiperConsumo é um termo muito mais antigo e tratado com maior profundidade, logo base para este estudo. Em alguns momentos vamos abordá-los com os nome distintos, apenas para citar o material de suas autorias, sendo que os textos levam a pontos distintos, ou seja, o teórico Gilles Lipovetsky aprofunda quanto a sociedade hiperconsumista direcionada para esta busca constante da felicidade, prazer reportados pela publicidade e o cinema, a felicidade passa a ser essencial para sociedade de consumo, enquanto a Hiperpublicidade é um complemento para este estudo, já que a obra organizada pelos professores Clotilde Perez e Ivan Barbosa, tratam dos fundamentos e interfaces na propagação, que leva ao consumo. Abaixo explicação sobre os termos:

\begin{abstract}
A hipermodernidade é caracterizada por uma cultura do excesso, do sempre mais. Todas as coisas se tornam intensas e urgentes. O movimento é uma constante e as mudanças ocorrem em um ritmo quase esquizofrênico, determinando um tempo marcado pelo efêmero, no qual a flexibilidade e a fluidez aparecem como tentativas de acompanhar essa velocidade. Hipermercado, hiperconsumo, hipertexto, hipercorpo, hiperpublicidade: tudo é elevado à potência do mais, do maior. O termo Hipermodernidade como idéia de exacerbação da Modernidade surgiu em meados da década de 70 e ganhou destaque em 2004 graças ao estudo de autores franceses e ao livro "Os tempos hipermodernos" do próprio Lipovetsky. (VALENTE, 2009, p.56)
\end{abstract}

O foco principal deste estudo é a Rede Globo, e a forma como a emissora está atuando durante a atual crise do COVID-19, conforme parte da opinião pública. Na busca de entendermos a opinião pública diante do que pensam sobre a veracidade da emissora, percebemos existir uma associação de ataques realizados por indivíduos "pro" e "contra" o governo atual, podemos considerar que as fake News se tornam destaque nas redes sociais, especialmente, por não necessitar de provas de sua fonte, associada à sua própria cultura de "tumultuar" as redes, não encontramos relação com uma pesquisa de campo, ou mesmo embasamento teórico, científico, analítico, qualitativo ou quantitativo, por parte dos ataques a emissora. Aqui apenas podemos afirmar que leitores e emissoras, qualquer indivíduo na rede, tem a obrigação de buscar fontes confiáveis para abordar qualquer tema, ou quando expor sua opinião, deve deixar transparente que é uma ideia opinativa, já que as associações das mensagens nas redes em massa geram conflitos e implica em diversos fatores negativos. enquanto a sociedade do hiperconsumo relacionado a felicidade pelo filósofo francês Gilles Lipovetsky, nos fez refletir sobre as relações do homem com o outro e como indivíduo. Estudo qualitativo e analítico, com questionário aplicado com 401 indivíduos aleatórios, criado na plataforma Google, por Raslan e Oliveira (2020), abordando a credibilidade da emissora Rede Globo. Com respaldo teórico sobre a sociedade de consumo e as transformações sociais atuais, a modernidade líquida pelo filósofo polonês Zygmunt Bauman foi de extrema importância, 
enquanto a sociedade do hiperconsumo relacionado a felicidade pelo filósofo francês Gilles Lipovetsky, nos fez refletir sobre as relações do homem com o outro e como indivíduo.

\section{HIPERCONSUMISMO: O FAKE NEWS PODE SER ESCLARECIDO PELA PROMOÇÃO DA INFORMAÇÃO}

É indubitável que, em decorrência da atual pandemia, a comunicação sofreu e vai continuar sofrendo aceleradas mudanças, que talvez apenas tenha sido acelerada, já que as redes sociais ainda parece ser a "terra ninguém", e a sociedade como um todo não se sente ameaçada por postar uma injúria ou uma falácia, tão pouco sente ameaçada judicialmente. Agora, mais do que nunca neste período de isolamento social, é importante analisarmos com atenção o papel que a comunicação tem em nossas vidas, como estávamos nos comunicando e como recebemos as mensagens. A mensagem não pode ser jogada na internet, profissional ou não, devemos refletir sobre a importância da informação e como esta interfere diretamente nas nossas atitudes.

Somente a título de contextualização, é importante destacarmos a origem e a finalidade inicial da publicidade. Existem diversos relatos que comprovam que a publicidade é muito mais antiga do que se pode imaginar, propagandas e anúncios já eram vistos desde o Egito antigo, feitas em papiros ou em alguns casos, como na venda de pessoas em situação de escravidão, os anúncios eram simplesmente gritados por quem estava anunciando - aqui é válido salientar que, apesar dos objetivos serem semelhantes aos da atualidade, a publicidade em seus primórdios não utilizava de metodologias para alcançar um público especifico (BADARÓ, 2014). O processo de evolução da publicidade ocorreu naturalmente ao longo dos anos, no entanto, foi em meados da Revolução Industrial que ela sofreu grandes mudanças, talvez, a maior tenha sido a perca de seu caráter informativo e adquirir uma característica mais persuasiva, e acabou por se tornar um dos mais notáveis pilares do capitalismo. Os veículos de comunicação são meios de conhecimento, de exorbitante importância, quando usado de forma adequada, pois é através dela que os indivíduos têm acesso à informação, a descrição e quaisquer outros atributos referentes as pessoas, serviços ou produtos, mesmo na propaganda de um produto a sociedade está sendo informada. Para Herman Benjamin (2001):

Não se confundem publicidade e propaganda, embora, no dia a dia do mercado, os dois termos sejam utilizados um pelo outro. A publicidade tem um objetivo comercial, enquanto a propaganda visa um fim ideológico, religioso, filosófico, político econômico ou social. Fora isso, a publicidade, além de paga, identifica seu patrocinador, o que nem sempre ocorre com a propaganda (HERMAN BENJAMIN, 2001, p. 270). 
Nesse viés, a publicidade é um processo comunicativo que necessita intimamente do uso adequado dos meios difusão, ou seja, a publicidade está intrinsecamente ligada às redes sociais, assim como seus recursos midiáticos. Logo, pode-se perceber que a tecnologia atua como uma grande facilitadora e amplia o acesso à informação, consequentemente facilita as formas de divulgação e de publicação, os meios de difusão midiática se tornaram ambientes saturados de mensagens com caráter informativo, e acabaram propiciando o cenário ideal para o surgimento das tão conhecidas Fake News. A publicidade é uma das ferramentas que podem ser usadas para mudar a imagem dos Fake News, sendo muito associada com o campo jornalístico, se faz necessário alterar esta baixa credibilidade de alguns discursos diante da imprensa, tendo impacto direto com os seus profissionais e a sociedade de forma mais incisiva.

Abaixo, imagem do site Tribuna da Internet, que diz que o Grupo Globo vai pesquisar fake news em meio a 133 milhões de postagens (fig. 01), e o gráfico dos indivíduos que têm acesso aos canais pagos e quanto a porcentagem que assiste à TV aberta (fig. 02).

Fig.01: Print do Tribuna da Internet em torno da Comunicação da Rede Globo, 2018

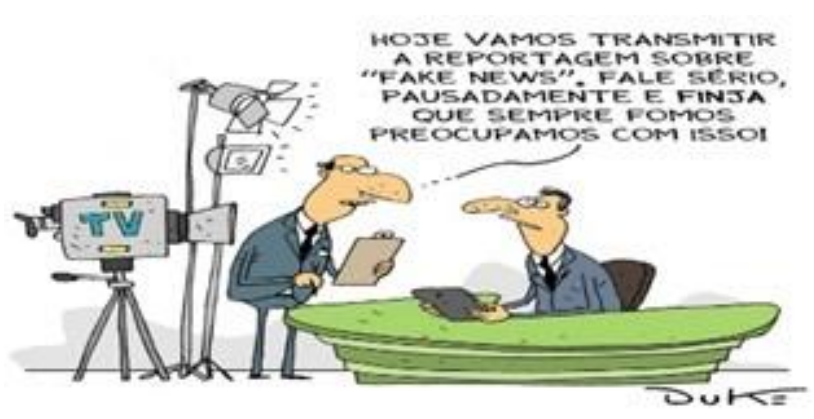

Fonte: COUTTO (2018)
Fig. 02: Print do Gráfico TV aberta assistidas na TV paga

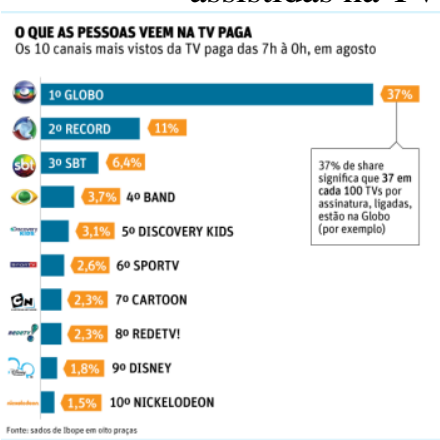

Fonte: FELTRIN (2020) e NASSIF (2020)

De forma humorada, a charge trata das Fake News no campo jornalístico, ela foi retirada da matéria de Coutto (2018), disponibiliza milhares de posts, cada post acessado te leva a outros diversos, que não parece ter fim. Adentrando nos assuntos em torno da Rede Globo de Televisão (2020b), acompanhada nacionalmente por uma audiência muito diversa, composta por várias faixas etárias e classes socioeconômicas, além dos programas que passam nos canais de TV aberta e as pagas, considerando que a maioria da sociedade tem acesso a TV não paga (aberta), vamos levá-la como apreço neste estudo, não analisando as repercussões em torno da TV paga (fechada). Sabemos que o conteúdo é diferenciado na TV paga, sendo que a produção da TV aberta é para massa e os programas são menos aprofundados e com matérias resumidas. 
De acordo com a Folha de São Paulo online, os canais mais vistos na TV pagam são a Rede Globo, Record, SBT e Band, sendo "cada 100 TVs por assinatura ligadas no Brasil, mais de 60 sintonizam os canais abertos na maior parte do tempo", o editor e colunista Ricardo Feltrin (2020) do F5 obteve dados inéditos sobre a TV paga relacionado a TV aberta. O programa do canal de televisão aberto da Rede Globo faz parte da programação massiva. O Grupo Globo detém grande parte da audiência brasileira, não vamos entrar aqui na questão cultural de ser um canal comum de acesso, onde as pessoas muitas vezes sintonizam em seu canal por costume, pela sua história envolvida, ou por exemplo, restaurantes e consultores médicos que deixam o canal ligado no seu período de funcionamento para o seu público.

Nesse sentido, podemos acreditar que a resposta dessa pergunta seja perturbadora, para não dizer difícil de conseguir uma resposta precisa. Justamente nesse domínio dos meios de interlocução, que faz com que a emissora esteja presente diariamente na vida dos cidadãos brasileiros, e acabe criando um cenário de Hiperconsumismo, que colabora muito para o surgimento das já referidas Fake News. Desse modo, perceba que uma notícia exposta em vários canais difusores, transparece uma sensação de verdade absoluta, o que faz com que a população deposite uma grande credibilidade nos informes emitidos pela emissora. Nesse sentido, faz se necessário realizar uma análise de como a HiperPublicidade está sendo usada de maneira errônea por pessoas comuns e até mesmo por canais de divulgação reconhecidos nacionalmente, gerando muito atrito e falta de respeito com os processos de informações verídicos e verificados pelos profissionais de comunicação. Aqui não vamos adentrar se a emissora da Rede Globo está sendo ou não manipuladora, quanto a veracidade dos fatos, e sim se a opinião pública acredita nesta veracidade.

Sobre a HiperPublicidade, buscamos Perez e Barbosa (2008a), ao tratarmos dos fundamentos e interfaces, eles entendem que o mais importante não é o que é dito, e sim como é dito, uma vez em que, esse "como" é o responsável por despertar as sensações que um discurso publicitário ou propaganda desejam provocar em um potenciais consumidores. Eles acreditam que a publicidade apresenta, entre seus muitos aspectos, uma caráter tridimensional ao trabalhar com a cognição: a capacidade que o discurso publicitário tem de transmitir saberes, ou seja, a capacidade de informar; como a interação: capacidade de influenciar os comportamentos do indivíduo; e a emoção: que é tocada em seus diversos âmbitos, mas sobretudo no querer, ou seja, na sensação de desejo. Dessa maneira, pode-se afirmar que a publicidade desempenha na sociedade, um papel de extrema importância, ao englobar estruturas sociais, econômicas e 
políticas, nesse sentido, as autoras Perez e Barbosa (2008a), afirmam "O discurso da publicidade aparece assim como porta-voz do sistema social e funciona como instrumento de comunicação e produção social, além de mascarar a intenção comercial tão explicitamente existente" (PEREZ e BARBOSA, 2008a, p. 10).

As atividades e tendências na HiperPublicidade para Perez e Barbosa (2008b) está na possibilidade de dissonância cognitiva, esta pode gerar uma expectativa errônea acerca do que será de fato entregue ao consumidor. Nesse âmbito, cabe estudar a postura que muitos dos veículos intercomunicativos adotam em relação à parcialidade do que será divulgado, pois é de suma importância que os informes apresentem, dentro das possibilidades, um caráter mais neutro, a fim de que os indivíduos utilizem do próprio senso crítico para escolher as informações que julgam ser verdadeiras, e assim serem capazes de formar opinião própria. Neste ponto, o jornalista da TV Globo deve preocupar quanta a promoção da informação, não basta uma fonte confiável, ele deve sempre ouvir os lados opostos, ou mesmo, a defesa do noticiado, para que o leitor tire suas próprias conclusões, deste modo, não abre brecha para dúvidas sobre a matéria.

Buscamos os pensamentos de Gilles Lipovetsky (2007a) em torno dos seus ensaios, ao abordar a sociedade de hiperconsumo o teórico trata da felicidade. Dificilmente iremos citar um conceito ou noção, já que nos leva a diversas associações, especialmente porque o ser humano em suas diversas linhas do tempo, procura a chave da felicidade, na certeza de que sua vida será mais satisfatória. O hiperconsumo está distribuído nesta fartura da felicidade contemporânea, resgatada em nossa herança mitológica - em Dionísio, Deus grego da alegria, assim como Deus da natureza, teatro e fecundidade. Para Lipovetsky (2007a) esta abundância de alegria é redescoberta na atualidade, logo o homem persiste nos deleites do corpo e sensações contíguas dentro de uma nova cultura diária. Esses efeitos e percepções imediatas está associado ao engano, mesmo que este momento feliz seja um hedonismo, não podemos esquecer que vem seguida por temores. Percebam que a propagação dos fake news está diretamente relacionado ao hiperconsumo tratado por Lipovetsky (2007a), o destaque não é o sentimento de insegurança e temores sobre o indivíduo e sim a propagação do engano - chamado pelo autor de"carpe diem". Nesse momento regredimos como ser humano, já que não enxergamos o culto do instante.

A HiperPublicidade está para forma como se diz algo e nos leva as interpretações, imagens e textos são planejados e passam por processos de criação, um planejamento dentro de novos formatos publicitários que alcança de forma rápida a comunidade virtual. Tem uma 
relação direta com o HiperConsumo, uma tentativa constante da renovação, marcada pela variedade, já que os desejos do ser humano os leva as associações inseguras. O homem parte do princípio do prazer, da novidade e do conhecimento, nesta sociedade moderna que se agarra as raízes do tempo, as relações de consumo a notícia são cada vez mais aceleradas, levando o indivíduo para uma armadilha do tempo atual, novas formas de publicidade são integradas nesta rotatividade diária da notícia, inovação da tecnologia com a decoração da promoção vinculada ao lazer de consumo, como as matérias jornalísticas que viraram foco a partir das falas de ataques do atual Presidente do Brasil, em sua defesa das notícias que não concorda ou lhe agrada, logo temos um jornalismo que necessita se propagar para ganhar confiança do público. Lipovetsky (2007a) trata do consumo-sedução, que está para esta fidelidade do homem atual em ser um fiel herdeiro, está abordando a vinculação deste lazer-consumo, ou seja: consumodistração. Torna-se relevante ressaltar que nenhuma fonte de informação, seja ela jornalística ou não, estaremos motivados por este consumo, uma nova forma de produção amarrada a esta sociedade da abundância, seja pelo consumo-lazer de uma notícia ou de um produto, se tornando incapaz de adquirir uma postura cem por cento imparcial, visto que a comunicação é feita por pessoas e que estas por sua vez, escrevem com base nos ideais que acreditam, o ser humano busca por esta felicidade amarrada aos volumes de promover, de renovar e de consumir. Logo, sugerimos que toda informação, quando houver caráter opinativo, que esta seja dita, esclarecida pela autoria, para que a sociedade saiba que é uma opinião próprio do profissional da emissora, citando fontes diversas e de cunho opinativos distintos, para que o leitor possa opinar a respeito sem ser conduzido.

A HiperPublicidade e o HiperConsumo estão difundidos nesta universalidade pelo gosto das mudanças, difundida ao modismo universal que recai sobre o desejo de experimentar, a novidade promete sabedoria e o consumo constante pela notícia equilibra as sensações e promete felicidade, não há necessidade de checar a fonte, neste momento a promessa satisfaz e gera laços sociais naquele grupo de reconhecimento sobre tal fake news, mas a posterior descoberta pela falsa verdade gera depressão e uma dificuldade de viver, gera ansiedade na sociedade hiperconsumista, esta frustrada pela falsa ideia de adquirir felicidade. A centralidade do consumo para Lipovetsky e Serroy (2011), está no momento que refletimos sobre o que as relações causam na sociedade, o exagero das práticas está para as possibilidades existentes no mundo, não adianta satanizar o consumo e sim refletir sobre os seus valores. Percebam que a alternativa sobre a reação do indivíduo quanto acreditar nas notícias da Rede Globo, está engajada na consciência deste consumo e como é construídas as relações nas redes, sociedade 
que se encontra desorientada com o excesso de informação, e atualmente, buscar fontes ou aprofundar em conteúdo não faz parte da "cultura-mundo", e sim, variedade informacional.

\section{PRÁTICA PUBLICITÁRIA: A COMUNICAÇÃO DA EMISSORA REDE GLOBO ESTÁ SENDO IMPARCIAL NA NOTÍCIA?}

Ao pensarmos em comunicação fica fácil citar a imprensa como meio de informação, já que ela impacta no que as pessoas acreditam, na forma como elas vivem, se comunicam e se informam, a percepção deste leitor sobre política e cultura pode ser esclarecida ou distorcida pelos profissionais de comunicação social, em vem sendo cada vez mais questionada, leitor que exige clareza e veracidade dos fatos apresentados, adquiridas pelos telespectadores em detrimento da grande quantidade de fake news presentes nos canais informativos. Mas também, por conseguinte, hoje podemos falar que as emissoras estão sendo acompanhados por um público muito mais crítico e atento, um dos motivos da enorme repercussão em torno das emissoras, estas não acostumadas a serem contrariadas ou colocadas diante da dubiedade. De fato, os profissionais de comunicação terão muito trabalho pela frente, para que possamos efetivamente desmistificar os efeitos causados pelas danosas fake news. A essa altura, é imprescindível esclarecer o contexto de surgimento da Rede Globo e os efeitos dela na política ao longo dos anos. A emissora foi fundada em 1965, um ano após o golpe de estado ocorrido em 1964 e se tornou a maior rede de televisão brasileira em meados da década de 1970, dessa maneira é evidente que a origem e a ascensão da emissora ocorreram durante a ditadura militar (REDE GLOBO, 2020a). Devemos considerar o período em que a instituição foi criada e para entendermos o seu papel na intervenção militar, durante os seus anos de ascensão, abaixo breve trecho do discurso em reconhecimento ao apoio dado ao regime militar brasileiro, proferido pelo fundador da Rede Globo, Roberto Pisani Marinho: "participamos da Revolução de 1964, identificados com os anseios nacionais de preservação das instituições democráticas, ameaçadas pela radicalização ideológica, greves, desordem social e corrupção generalizada.” Trata da redação que "foi invadida por tropas antirrevolucionárias, mantivemo-nos firmes a nossa posição.” (CARTA MAIOR, 2013.).

O cenário e conteúdo da TV não alterou seu formato desde os anos 2000, linguagem amarrada ao apresentador dos jornais que noticiam horários dos programas e as notícias, "a linguagem utilizada no Jornal Nacional e, posteriormente, em outros telejornais da rede era intimista. Pensava-se 'numa família brasileira reunida na sala de jantar, em torno da televisão', tal como antes ocorrera com o rádio". E não podemos esquecer das fortes e das curtas manchetes 
do Jornal Nacional, sendo que "os apresentadores liam o noticiário alternadamente de maneira ágil”. (BARBOSA, 2005, p. 212). Todavia, em 2013, a GLOBO (2020a) caracterizou por meio de uma nota publicada em seu site, como erro o suporte dado ao golpe de 1964. O texto foi divulgado em meio a publicação do projeto "Memórias" que relembrou os 88 anos de história do jornal O Globo, fundado por Roberto Irineu Marinho. Nele, a instituição afirmou que o apoio ao regime militar ocorreu devido ao temor de um outro golpe, por parte do então presidente João Goulart, apoiado pelos sindicatos. Contudo, ao noticiar grandes momentos da história, principalmente acontecimentos ocorridos durante o regime militar, como por exemplo o movimento das Diretas Já, por FANTINATTI (2007), que foi associado pela emissora ao aniversário de 430 anos de São Paulo, e apresentado como parte das comemorações ao aniversário da cidade, a Rede Globo ao transpor mensagens adulteradas, passou a ser conhecida como uma emissora manipuladora. Todavia, ao refletir sobre o contexto que paira sob a Rede Globo, sabemos que devemos considerar que o ser humano é falho e que os profissionais de jornalismo também podem falhar quanto a questão da imparcialidade dada a notícia, mas estes já na academia, estudam sobre a importância da ética profissional e da notícia a partir da veracidade, e sobretudo, quando houver sua opinião, que esta seja especificada, algo que notamos com frequência nas emissoras de TV e Rádio realizarem correção posterior, por muitos jornalistas que fazem que anunciaram erroneamente. A forte influência política sempre existiu e sabemos que nas últimas eleições ela se destacou, dessa maneira, é fácil perceber que o cidadão comum passou a opinar com mais frequência nas redes e que as divergências políticas interferem nas matérias publicadas, já que o cidadão passa a criticar e a publicar seu próprio conteúdo, este de modo geral, sem conferir as fontes. No cenário mais atual a repercussão tem aumentado, estamos no ano de 2020 em torno da pandemia mundial - COVID-19, no caso do Brasil, o atual presidente Jair Messias Bolsonaro vem sendo alvo quase que diário de duras críticas advindas do grupo Globo, e o questionamento a ser feito agora é: porque o atual Presidente da República está na mira de tantas críticas por parte da Globo?

Hipóteses é o que mais teremos, seja pelo seu jeito "tosco" de se anunciar as mídias em sua defesa, ou mesmo ao criticar os adversários políticos e chamar a emissora de esquerdista, ou ainda podemos buscar material que comprove ser uma estratégia política do governo atual ou da própria emissora, aqui não buscamos fontes para comprovar tal hipótese, mas vamos relatar alguns fatos exibindo interesses de ambos os lados, e que seria necessário diversas direcionamentos, para afirmar imparcialidade na notícia, não colocamos números ou porcentagem de veemências, já que são diversas as possibilidades de argumentação nesta linha 
das críticas. Consoante ao site Cesar Galeano (2019), ao longo dos anos a TV Globo acabou acumulando uma dívida milionária, que em 2007 já somava incríveis R \$ 615 milhões, em decorrência de um processo de sonegação de impostos, dinheiro este que não havia sido veemente cobrado até a posse do presidente Bolsonaro. Outrossim, ainda de acordo com o site Cesar Galeano (2019), a concessão da emissora vence no dia 5 de outubro de 2022, dois meses e meio antes de Bolsonaro deixar a presidência ou renovar seu mandato, e o presidente afirmou que não assinará o decreto de renovação da concessão, enquanto a instituição estiver em dívida com a União ou envolvida em processo de sonegação. Nessas circunstâncias, é fácil perceber que determinados acontecimentos, podem ter motivado a milionária rede de comunicação a hostilizar o atual Presidente da República, entretanto, não existe qualquer motivo que sirva como justificativa aos "ataques midiáticos" e a manipulação de informações proferidas pela instituição, ou por qualquer outro meio comunicativo, sendo que as afirmativa de Galeano (2019) são hipóteses, não sendo motivo para colocar em dubiedade a informação da emissora. Em paralelo à rivalidade entre a TV Globo e o presidente Jair Bolsonaro, neste momento da pandemia causada pelo novo Coronavírus, o Sars-CoV-2, continua crescendo no Brasil e no mundo, já que as notícias da emissora espalham internacionalmente, contudo, neste momento sabemos que a população necessita de mensagens claras e precisas sem deixar em dúvida o papel de informar do presidente e da emissora.

Difícil afirmar de onde tais dúvida sobre a verdade surgiu, que tal nuvem negra que paira sobre a imprecisão da notícia em torno da presidência e da imprensa aumentam cada vez mais ao aproximarmos das próximas eleições, com certeza seria uma ótima pesquisa para os estudiosos com interesse na área. O que sabemos é que o eleitorado é “manipulado" por partidos e pela imprensa, especialmente porque a maioria do eleitorado não checa os fatos e acreditam nas mensagens que receberam, ou querem acreditar por ser favoráveis as suas verdades, ainda sem submergir na questão do fator emocional das preferências partidárias que podem alterar os fatos e a repercussão da matéria, seja este profissional de comunicação ou leitor, logo o telespectador precisa se atentar quanto às notícias apresentadas pela Rede Globo, associadas ao Presidente, e vice-versa, a regência em relação aos acontecimentos acarretados pela pandemia do Covid-19 devem ser noticiadas com respeito, seja a imprensa e ou o chefe de Estado, ambos tem obrigação com a verdade e os mesmos deveriam responder criminalmente. Sendo assim, para avaliar a situação de forma justa e não alienada, é palpável que o público se valide de mais de uma fonte de informação, considerando que no Brasil existem diversas emissoras de televisão e que servem como fonte de informação, além de material governamental publicado 
pelas imprensas privadas e os diversos setores do governo, inclusive as universidades. Não há como assumir uma postura a partir de apenas uma fonte como verdade.

Nesse contexto, buscamos as práticas publicitárias por Sant'Anna (2015), afirma que necessitam de planejamento para serem executadas, sendo que as funções, os métodos avaliativos e os posicionamentos devem ser feitos com inteligência, considerando que o respeito ao leitor parta da informação verídica. Para o autor, o conceito de marketing (MKT) passa por todas atividades relacionadas à movimentação de mercadorias e serviços, sendo assim, pode-se interpretar, de forma lírica, que o "serviço" é um dos produtos da política, uma vez que os políticos são eleitos para representar e prestar serviços à população. Nesse quesito, nota-se que o MKT é uma ferramenta de extrema relevância para notícia, pois é através das campanhas desenvolvidas que o público se informa sobre os candidatos políticos ou sobre os representantes já nomeados, e é aqui que a comunicação de massa exerce um de seus papéis de forma mais expressiva, ao apresentar discursos eleitorais e(ou) simplesmente ao disseminar notícias relacionadas aos candidatos. Em contrapartida, diversos Fake News são disponibilizados na internet questionando a veracidade das notícias quanto a TV Globo, em relação à política. São muitos e cada uma delas levaria a uma cadeia de fatos para averiguar quem a criou, quem a publicou e quem a disseminou, ainda, quem conseguiu a partir delas ganhar repercussão. Mas, independentemente se é verdade ou não, sabemos que verificar a sua veracidade para que a sociedade não seja manipulada é uma obrigação da imprensa e do governo que representa a sociedade, as propagações das reportagens da própria emissora Globo e de outras emissoras podem correr atrás dos fatos para comprovar a verdade. Sabemos que ao realizar cortes de informações que podem alterar o sentido da notícia em uma análise feita fora de contexto pode causar grande repercussão social, e ao realizar uma possível escolha de palavras que possuem um alto teor de influência, fortalece a propagação de inverdades, contrariando o Código de Ética da FENAJ do Brasil (2007), Federação Nacional dos Jornalistas, que teoriza que "O compromisso fundamental do jornalista é com a verdade dos fatos, e seu trabalho se pauta pela precisa apuração dos acontecimentos e sua correta divulgação". A própria imprensa deve usar do seu próprio meio, para se defender de falácias, mas para isto precisa buscar provas e trabalhar com fatos verídicos. Abaixo, imagem (fig.03) da matéria da Rede Globo (2019):

Fig.03: Print do site da Emissora Rede Globo esclarecendo os ataques do Governo Bolsonaro

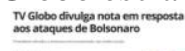

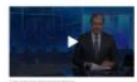

Fonte: REDE GLOBO (2019) 
Neste vídeo e texto, publicaram uma resposta aos ataques do presidente Bolsonaro, podemos perceber que as redes de comunicação de massa possuem grande influência sobre a política, uma vez em que elas são consideradas, por boa parte da população, como bons veículos de comunicação de massa, e é a partir daí que surge na população a necessidade de receber as notícias da forma mais neutra possível, afim de não privilegiar ou desfavorecer ninguém e nenhuma das partes. Os canais de comunicação são importantíssimos para sociedade, para divulgar e esclarecer abusos de poder e direitos dos ser humano.

\section{O QUE AS PESSOAS PENSAM SOBRE A COMUNICAÇÃO DA EMISSORA REDE GLOBO? ATAQUES CONTRA A CREDIBILIDADE INFORMACIONAL}

Considerando os assuntos tratados neste artigo, realizamos uma pesquisa quantitativa, com valor amostral mensurado em quatrocentos e um (401) participantes, feita a partir de um questionário disponibilizado na internet, através um link da plataforma de formulários do Google, o questionário iniciou no dia 15 de maio à 20 de maio do ano de 2020, que pôde ser compartilhado em todas as redes sociais pelos próprios participantes. As respostas foram apuradas com apenas cinco (5) dias de resposta, entre o dia por um público de idade mínima de 18 anos, no entanto, a faixa etária que obteve maior porcentagem de respostas foi classificada entre os usuários de 20 a 40 anos de idade.

A pesquisa foi analisada e percebemos que a maior parte dos telespectadores acredita parcialmente ou totalmente nas informações da emissora, que muitas das notícias apresentadas pela Rede Globo apresentam mensagens distorcidas, também podemos concluir que a maior parte dos colaboradores da pesquisa assistem à algum noticiário transmitido pela própria emissora, entretanto maior parte dos votos foram assinalados como parcialmente ou completamente, quanto as informações apresentadas serem distorcidas e que isso acaba de alguma forma sendo prejudicial à imprensa, já que sua credibilidade fica abalada e consequentemente os créditos aos profissionais de jornalismo diminuem. Em decorrência das questões tratadas nesse artigo, também buscamos saber o que as pessoas pensam sobre a parcialidade política da imprensa e as respostas mostraram que a maioria dos participantes acredita que a Rede Globo de Televisão ao disseminar as notícias, apresenta um caráter tendencioso e mais favorável em relação a sua preferência partidária, também constatamos que, embora 40,6\% dos colaboradores avaliarem que as notícias divulgadas na internet sobre o 
partidarismo da emissora seja algo do atual governo, 59,4\% dos votantes não acreditam ou acreditam parcialmente que essas notícias façam parte exclusivamente do governo Bolsonaro. Por tanto, pode-se afirmar que a credibilidade da Rede Globo se encontra questionável diante de seus telespectadores, implica em consequências negativas para a instituição, uma vez que duvidar da veracidade dos fatos de uma emissora, abala a credibilidade, tende a perder a confiança dos telespectadores, além de manchar a imprensa de modo geral. Este estudo é apenas uma base de outros tantas fontes que devem ser apuradas sobre a confiança da sociedade diante dos meios de comunicação, quanto a verdade noticiada nas redes sociais, e o motivos de dar credibilidade aos Fakes News. Abaixo, prints de algumas páginas do formulário Google:

Fig.04-05: Print de algumas páginas da internet, Gráfico de respostas do Formulário

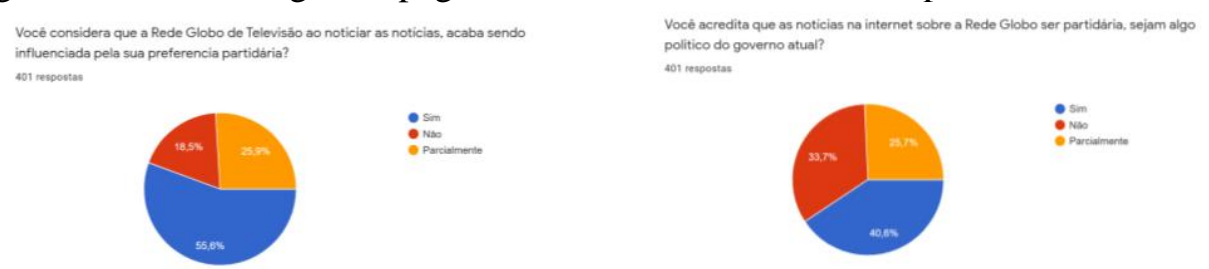

Fonte: RASLAN e OLIVEIRA (2020)

A partir da pesquisa notamos o quanto as notícias que geram dramaticidade e falácia caem no gosto do público, como os Fakes News, chamando a atenção e ganhando repercussões enormes. Abaixo na Tabela 1, de autoria própria, algumas informações sobre os indivíduos que responderam o questionário,

Tabela 1 - Referência sobre os participantes que responderam o questionário

\begin{tabular}{|c|c|c|c|}
\hline Idade & Percentual & \multicolumn{2}{|c|}{$\mathrm{N}^{\circ}$ de pessoas } \\
\hline Até 20 anos & $32,9 \%$ & \multicolumn{2}{|l|}{132} \\
\hline Entre 21 e 40 anos & $46,9 \%$ & \multicolumn{2}{|l|}{188} \\
\hline Acima de 40 anos & $20,2 \%$ & \multicolumn{2}{|l|}{81} \\
\hline \multirow[t]{2}{*}{ Acompanha algum Telejornal da Rede Globo? } & SIM & NÃO & Parcialmente \\
\hline & $\begin{array}{l}63,3 \% \\
254 \text { pessoas }\end{array}$ & $\begin{array}{l}36,7 \% \\
147 \text { pessoas }\end{array}$ & $\begin{array}{l}0 \% \\
0 \text { pessoas }\end{array}$ \\
\hline \multirow[t]{2}{*}{$\begin{array}{l}\text { Acredita que muitas informações televisivas da Rede Globo têm sua } \\
\text { mensagem distorcida? }\end{array}$} & SIM & NÃO & Parcialmente \\
\hline & $\begin{array}{l}40,6 \% \\
163 \text { pessoas }\end{array}$ & $\begin{array}{l}15,5 \% \\
62 \text { pessoas }\end{array}$ & $\begin{array}{l}43,9 \% \\
176 \text { pessoas }\end{array}$ \\
\hline \multirow[t]{2}{*}{$\begin{array}{l}\text { Referente as notícias na internet sobre a Rede Globo de omitir } \\
\text { informações e ou notícias, você acredita que pode ser prejudicial a } \\
\text { imprensa? }\end{array}$} & SIM & NÃO & Parcialmente \\
\hline & $\begin{array}{l}71,8 \% \\
288 \text { pessoas }\end{array}$ & $\begin{array}{l}9 \% \\
36 \text { pessoas }\end{array}$ & $\begin{array}{l}19,2 \% \\
77 \text { pessoas }\end{array}$ \\
\hline \multirow[t]{2}{*}{$\begin{array}{l}\text { Considera que a Rede Globo de Televisão ao noticiar as notícias, acaba } \\
\text { sendo influenciada pela sua preferência partidária? }\end{array}$} & SIM & NÃO & Parcialmente \\
\hline & $\begin{array}{l}55,6 \% \\
233 \text { pessoas }\end{array}$ & $\begin{array}{l}18,5 \% \\
74 \text { pessoas }\end{array}$ & $\begin{array}{c}25,9 \% \\
104 \text { pessoas }\end{array}$ \\
\hline \multirow[t]{2}{*}{$\begin{array}{l}\text { Acredita que as notícias na internet sobre a Rede Globo ser partidária, } \\
\text { sejam algo político do governo atual? }\end{array}$} & SIM & NÃO & Parcialmente \\
\hline & $40,6 \%$ & $33,7 \%$ & $25,7 \%$ \\
\hline
\end{tabular}




\begin{tabular}{|c|c|c|c|}
\hline & 163 pessoas & 135pessoas & 103 pessoas \\
\hline $\begin{array}{l}\text { Sabendo que "O respeito à verdade e ao direito do público à verdade é } \\
\text { a } 1^{\text {a }} \text { obrigação do jornalista", de acordo com o Código de Ética } \\
\text { FENAJ/Brasil, você considera que a comunicação da TV Rede Globo é } \\
\text { imparcial? Ou seja, não privilegia ninguém e nenhuma parte? }\end{array}$ & SIM & NÃO & Parcialmente \\
\hline & $\begin{array}{l}21,9 \% \\
88 \text { pessoas }\end{array}$ & $\begin{array}{l}58,9 \% \\
\text { 236pessoas }\end{array}$ & $\begin{array}{l}19,2 \% \\
77 \text { pessoas }\end{array}$ \\
\hline
\end{tabular}

Fonte: RASLAN e OLIVEIRA (2020).

Os Fake News distribuídos nas diversas redes da internet, para tratarmos da credibilidade da imprensa da Rede Globo, é uma delas, ganham tanta importância quanto uma notícia em torno da tragédia, conseguir audiência a partir do drama virou algo comum na imprensa, neste caso, também vem sendo usado para ganhar repercussão política, porém usada sem ética e sem apuração dos fatos, simplesmente são criadas e distribuídas nas redes sociais, do mesmo modo, indivíduos comuns, carismáticos por um determinado partido, contribuem para disseminar a notícia falsa. Desse modo, levantamos a importância de os profissionais de comunicação, necessitar buscar trabalhar sua imagem diante do público, para que indivíduos da área política não aproveitem da falta de informação da sociedade e ganhem visibilidade a partir da falta de credibilidade da imprensa. Se partirmos da exigência apoderada no mundo capitalista, para Bauman (2003) a ordem está para o consumo, não há lugar que pertença a alguém, já que há uma confusão entre espaço e tempo, não havendo mais compromisso um com o outro, podemos usufruir à vontade. As reações do indivíduo diante da notícia, de ser ou não verdade, tem relação com o outro, recusamos em reconhecer o estranho (antropoêmica) e a comodidade vem da ameaça a nossa segurança, destruímos o que não gera conforto (antropofágica). Logo, o HiperConsumo da informação está para a propagação utilizada da maneira correta, pode influenciar a sociedade de forma positiva, de modo a trazer grandes benefícios para a população, neste momento do Coronavírus estamos frágeis e temos dúvidas se os leitos estão no limite para receber pacientes ou não, então propagar a verdade e salvar vidas em razão da vasta gama de conteúdos relacionados a prevenção, a evolução e a diversos outros aspectos desta doença, é uma prioridade. A potencialidade do consumidor com os objetos de consumo, de acordo com Bauman (2008), está para interação e encontros desta sociedade de consumidores, que está dividida entre escolher as coisas e quem as escolhem, logo estamos sujeitos a frustação gerada pelos efeitos diretos deste consumo. Essa perspectiva sobrecarregada o indivíduo levando-o a incômodos, logo podemos considerar o lixo virtual que ocupamos, nos espaços da internet, com intrigas políticas e partidárias geradas pelo consumo da informação muitas falaciosas, que irão gerar este inconveniente tratado pelo autor. Desse modo, podemos concluir que a HiperPublicidade é fruto do árduo trabalho dos profissionais de comunicação, e 
que ela deve ser usada de maneira sábia para que seus efeitos possam ir muito além da divulgação de mensagens e possa trazer melhorias para a população mundial, uma vez que a tecnologia e o processo de globalização contribuem para compartilhar saberes entre pessoas.

\section{RESULTADOS E DISCUSSÃO}

Percebemos a partir de Bauman que a autoconfiança é sustentada pela produção de capital, e como o mercado produtivo flui em pouco espaço gerando competitividade, lutamos para sobreviver e não sentimos amparados com tanta informação nas redes. O materialismo está nesta sociedade produtora que gera solidez e segurança ao sujeito, são estas relações do HiperConsumo que não podemos considerar ser somente uma consequência da tecnologia, como também, ponderar que é um dos grandes suportes do capitalismo, que por sua vez, exprime na sociedade hábitos cada vez mais consumistas, sendo que a própria informação se torna um meio de consumo, o indivíduo se sente isolado e as relações o torna cada vez mais fragilizado. Ao todo a credibilidade da Rede Globo não é ruim, mesmo assim a baixa credibilidade é algo em que ela deve se preocupar, já que o indivíduo nas redes opina, cria e divulga conteúdo. No contexto do HiperConsumo/HiperPublicidade, podemos considerar que a Rede Globo, assim como outras instituições, possui uma forte influência sobre a maneira de pensar dos seus consumidores, como visualizam os acontecimentos políticos, econômicos e sociais. Percebemos com Lipovetsky (2007) que a natureza do homem e suas potencialidades são afetadas pelo imperialismo e ainda pelo próprio exagero, então não devemos acusar o consumo, deve existir equilíbrio para que a sociedade consiga se estruturar, não necessitamos experimentar apenas porque determinado indivíduo ou emissora é excepcional ou porque as coisas são necessárias para que alcancemos o prazer, com o fortalecimento da publicidade, também contribuiu para as que empresas motivem o consumo-sedução, fidelizando o consumodistração, já que o sujeito está para "obsolência programada" deste estilo de vida cotidiano, relacionada ao privilégio do lazer, numa busca da felicidade, logo as associações do indivíduo está para suas emoções e como a sociedade atual funciona nas suas relações, a repercussão nas redes é um atrativo para o indivíduo, que consome com intensidade e o satisfaz, associado a felicidade imediata de opinar, o problema são as contrarreações opinativas, que geram uma crescente instabilidade nas redes que se torna fluída, como uma sociedade líquida, que substitui o consumo de forma instantânea, já que não há planejamento. Nessa perspectiva, podemos afirmar que tanto o Estado, a Mídia e a Sociedade devem lutar pela veracidade e direitos a 
comunicação, considerando o atual cenário de pandemia, verificamos que diante do questionário respondido, a opinião está mais direcionada quanto a confirmação que a Rede Globo manipula o espectador, porém quanto a probabilidade quantitativa não fica comprovado que a emissora está sendo parcial ao informar os acontecimentos gerais, já que devemos considerar que seja baixo o número de indivíduos que responderam o questionário para tal confirmação, diante da variedade cultural e geográfica dos espectadores da emissora. Ainda carece levar em conta que a interferência política e seus seguidores, neste momento de forte atrito entre o eleitorado da direita e da esquerda no Brasil, podem interferir na opinião deste público, diante da falta de retorno da emissora para estes grupos de direita.

\section{REFERÊNCIAS}

ANAHP - Associação Nacional de Hospitais Privados. 17.02.2020. Veja o que se sabe até agora sobre o novo coronavírus chinês. Disponível em: <https://www.anahp.com.br/dados-do-setor/> Acesso em: 11 maio 2020.

BADARÓ, Wilson Oliveira Badaró. A cura em Kemet entre 1700 e 1500 a.c.: anotações, caracterização e conteúdo do papiro de Edwin Smith. Revista Eletrônica Discente História.com, Cachoeira, v. 5, n. 9, p. 89-107, 2018.

BARBOSA, M. C.; RIBEIRO, Ana Paula Goulart. Telejornalismo na Globo: Vestígios, narrativa e temporalidade. In: Cesar Bolaño; Valério Cruz Brittos. (Org.). TV Globo: 40 anos de poder e hegemonia. 1 ed. São Paulo: Paulus, 2005.

BAUMAN, Z. Modernidade líquida. Trad. Plínio Dentzien. Rio de Janeiro: Zahar, 2003.

Vida para o consumo: a transformação das pessoas em mercadorias. Trad. Carlos Alberto Medeiros. Rio de Janeiro: Zahar, 2008.

BRASIL. Portaria $\mathbf{n}^{\circ}$ 356, 11 de março de 2020. Institui a regulamentação e operacionalização do disposto na Lei $\mathrm{n}^{\circ} 13.979$, de 6 de fevereiro de 2020, estabelecendo as medidas para enfrentamento da emergência de saúde pública decorrente do coronavírus (COVID-19). Diário Oficial da União, Brasília, DF, 12 de março de 2020. Disponível em: <http://www.in.gov.br/en/web/dou/-/portaria-n-356-de-11-de-marco-de-2020-247538346>

Acesso em: 10 de março de 2020. 
CARTA MAIOR. 01.04.2013. O editorial de Roberto Marinho que exaltou a Ditadura Militar. Editorial Militar, 2013. Política. Disponível em: <https://www.cartamaior.com.br/?/Editoria/Politica/O-editorial-de-Roberto-Marinho-queexaltou-a-Ditadura-Militar/4/27682/> Acesso em: 16 março 2020

CEPCCOM. (2019). Centro de Editoração, Publicações e Criações em Comunicação. MG, Divinópolis: UEMG. Disponível em: <https://cepccomuemg.wixsite.com/cepccom> Acesso em: 26 set 2020.

CÓDIGO CONSUMIDOR. Antônio Herman de Vasconcelos e Benjamin, Código de Defesa do Consumidor Comentado pelos autores do Anteprojeto. São Paulo: $7^{\mathrm{a}}$ Ed., 2001.

COUTTO, Pedro. 31.07.2018. Sob o Signo da Liberdade: Grupo Globo vai pesquisar "fake news em 133 milhões de postagens". Tribuna da Internet. Disponível em: <http://www.tribunadainternet.com.br/grupo-globo-vai-pesquisar-fake-news-em-133milhoes-de-postagens/> Acesso em: 16 março 2020.

FANTINATTI, Márcia. A cobertura jornalística da campanha pelas "Diretas já": o fantasma que ainda assombra a história da Rede Globo. Intercom - Sociedade Brasileira de Estudos Interdisciplinares da Comunicação V Congresso Nacional de História da Mídia - São Paulo - 31 maio a 02 de junho de 2007.

FELTRIN, Ricardo. Globo, Record, SBT e Band: são canais mais vistos da TV paga. Jornal Folha de São Paulo. Editor e colunista do F5. Disponível em: <https://f5.folha.uol.com.br/colunistas/ricardofeltrin/989647-globo-record-sbt-e-band-saocanais-mais-vistos-da-tv-paga.shtml>. Acesso em: 10 março 2020.

FENAJ. Código de Ética dos Jornalistas Brasileiros. Federação Nacional dos Jornalistas, 2007. Disponível em:<https://fenaj.org.br/codigo-de-etica-dos-jornalistasbrasileiros-19852007//> Acesso em: 21 março 2020

LIPOVETSKY, G. A felicidade paradoxal: ensaios sobre a sociedade de hiperconsumo. Trad. Maria Lúcia Machado. São Paulo: Companhia das Letras, 2007.

LIPOVETSKY, G.; SERROY, J. Cultura-mundo: resposta a uma sociedade desorientada. São Paulo: Companhia das Letras, 2011.

NASSIF, Luis. Luis Nassif Online. Jornal GGN, O jornal de Todos os Brasis. Disponível em: 〈https://jornalggn.com.br/luisnassif/>. Acesso em: 10 março 2020. 
PEREZ, Clotilde; BARBOSA, Santos. (Org). HiperPublicidade: Fundamentos e Interfaces. v.1. São Paulo: Cengage Learning, 2008a.

(Org). HiperPublicidade: atividades e tendências. v.2. São Paulo: Cengage Learning, 2008b.

RASLAN, E. M. S.; OLIVEIRA, M. M. de. O que você acha da Rede Globo de Televisão? Gráfico de respostas de Formulários da Plataforma do Google. Oi Todo mundo! Site do Google, criado no dia 15.03.20 e finalizado no dia 20.03.2020. Disponível em: <https://forms.gle/Sw9kPHF2csQ9371u9/>. Acesso em: 29 setembro 2020.

REDE GLOBO. Diretas já: movimento pedia o voto direto, a ditadura militar já completava seus 20 anos quando o povo começou a organizar eventos que pediam a eleição direta. Educação Globo. Redação. Disponível em: <http://educacao.globo.com/artigo/diretas-ja-movimentopedia-o-voto-direto.html >. Acesso em: 29 setembro 2020a.

—. Rede Globo de Televisão Brasileira. Disponível em: <https://redeglobo.globo.com/> Acesso em: 10 março 2020 b.

30.10.2019. TV Globo divulga nota em resposta aos ataques de Bolsonaro: Presidente ofendeu a emissora em transmissão nas redes sociais G1. Disponível em: $<$ https://g1.globo.com/jornal-nacional/noticia/2019/10/30/tv-globo-divulga-nota-em-respostaaos-ataques-de-bolsonaro.ghtml> Acesso em: 29 setembro 2020.

SANARMED. Linha do tempo do Coronavírus no Brasil. Sanar Med, 2020. Disponível em: $\quad$ ehttps://www.sanarmed.com/linha-do-tempo-do-coronavirus-no-brasi/> Acesso em: 10 maio 2020

SANT'ANNA, Armando. Propaganda: teoria, técnica e prática. São Paulo: Cengage Learning, 2015.

VALENTE, S. B. M. Entre o inferno e o paraíso: o papel da publicidade na sociedade de hiperconsumo. Revista editada pela Sociedade Brasileira de Estudos Interdisciplinares da Comunicação - Intercom. Ano2. \# 3, Edição bimestral, maio e junho de 2009.

Recebido em: 10 de Agosto de 2020.

Aceito em: 11 de Novembro de 2020. 